\title{
A construção discursiva dos imigrantes na imprensa
}

The discursive construction of immigrants in the press

La construction discursive des immigrés dans la presse

Maria João Silveirinha e Ana Teresa Peixinho de Cristo

\section{CpenEdition}

\section{Journals}

Edição electrónica

URL: http://journals.openedition.org/rccs/1343

DOI: $10.4000 /$ rccs. 1343

ISSN: 2182-7435

\section{Editora}

Centro de Estudos Sociais da Universidade de Coimbra

Edição impressa

Data de publição: 1 Outubro 2004

Paginação: 117-137

ISSN: 0254-1106

\section{Refêrencia eletrónica}

Maria João Silveirinha e Ana Teresa Peixinho de Cristo, « A construção discursiva dos imigrantes na imprensa », Revista Crítica de Ciências Sociais [Online], 69 | 2004, colocado online no dia 01 outubro 2012, criado a 20 abril 2019. URL : http://journals.openedition.org/rccs/1343 ; DOI : 10.4000/ rccs. 1343 


\title{
A construção discursiva dos imigrantes na imprensa'
}

\begin{abstract}
A identidade pública dos imigrantes depende de um conjunto de factores que vão das práticas do Estado na sua regulamentação à intervenção institucional das diferentes organizações. Os imigrantes raramente têm uma palavra a dizer na construção desta identidade, uma vez que o seu acesso ao espaço público é quase nulo. No nosso texto procuramos averiguar, num dos lugares privilegiados da construção desta imagem - a imprensa -, como o discurso jornalístico cruza um conjunto de vozes e de actores, construindo episódios e "histórias" que focalizam as questões da imigração. Para o efeito, partimos do discurso dos textos jornalísticos e analisamos três excertos noticiosos, procurando dar conta de como se constroem na imprensa as identidades dos diferentes actores envolvidos.
\end{abstract}

\section{Introdução: A narrativa noticiosa e a construção discursiva da imigração} A situação dos diversos grupos imigrantes no mundo é complexa e diversa. As identidades de cada um desses grupos variam, de forma inter-grupal, pelos diferentes modos como a comunidade se diferencia interna e externamente, mas também de forma importante pelos discursos e práticas que enfrenta, condicionadores do seu estatuto político-social, mas igualmente condicionadores de uma identidade pública construída de diferentes modos. A percepção pública dos imigrantes depende, com efeito, de um conjunto de factores que vão das práticas do Estado à intervenção institucional. Nela, os imigrantes raramente têm uma palavra a dizer, uma vez que o seu acesso ao espaço público é quase nulo, o que significa que a sua identidade pública foge quase inteiramente ao seu controlo.

Um dos lugares privilegiados de construção desta imagem são, precisamente, os media, locus de uma cultura pública entendida como conjunto de

\footnotetext{
${ }^{1}$ Este texto faz parte do projecto de investigação "Media, Imigração e Minorias Étnicas" desenvolvido em 2003 no Instituto de Estudos Jornalísticos da Universidade de Coimbra para o Alto Comissariado da Imigração e Minorias Étnicas.
} 
símbolos, normas e valores, visões do mundo e formas comunicacionais comuns a pessoas e grupos que interagem num espaço público. No seu seio, perpassa o discurso jornalístico, que cruza um conjunto de vozes e de actores que vão desde as instituições do Estado às organizações da sociedade civil e, mais rara e circunstancialmente, aos imigrantes.

Este cruzamento não produz resultados homogéneos: factores muito diversos que vão da linha editorial do medium, aos que se prendem com a lógica mediática - por exemplo espaço disponível, prioridades de agenda, disponibilidade de jornalistas mais ou menos "especializados", e mesmo factores sazonais - fazem variar o discurso jornalístico. A isto se acrescenta o facto de os media serem domínios da comunicação com uma estrutura comunicativa específica que proporciona conteúdos que se tornam públicos ou acessíveis tanto ao conhecimento como ao debate, expressando o conteúdo definido por Stuart Hall como "idioma público". Este idioma não é homogéneo, porque a sociedade também não o é (Hall, 1978: 48) e porque cada meio cria a sua própria versão dele, em função da audiência a quem se dirige. O próprio Hall enfatiza que "A linguagem usada será, assim, a versão que o jornal faz da linguagem do público a que se dirige primordialmente" (Hall, 1978: 48). Estes "modos de se dirigir ao público" estão, por sua vez, relacionados com os conceitos de "codificação e descodificação" introduzidos nos anos 80 pelo mesmo autor, a propósito do discurso televisivo, para integrar texto e público no que ele designa por "políticas de significação" (Hall, 1980: 136). O texto define um campo de significação e, a partir dele, o acesso aos discursos que estão inscritos no texto.

No discurso jornalístico, é, no entanto, possível encontrar regularidades e características bem documentadas numa vasta literatura sobre os media, como a prevalência das fontes oficiais, a sua tendência a orientar-se para o acontecimento e não para a problemática ou a tendência para a narrativização. Por outro lado, há que recordar que o discurso noticioso nunca ocorre num vácuo político, económico ou ideológico, mas serve como filtro para organizar a realidade. Por esta razão, uma crescente literatura dos media visa a sua função ideológica, dando prioridade de análise às formas simbólicas à estrutura das notícias e não tanto ao seu conteúdo factual (Tuchman, 1978; Barkin, 1994; Bennett e Edelman, 1985). O trabalho sobre temas familiares e a necessidade de produzir sentido igualmente familiar faz dos jornalistas "contadores de histórias" que, na sua narrativização dos acontecimentos, produzem e cultivam identidades políticas e culturais. Enquanto outras abordagens à análise das notícias, como as de gatekeeping ou as que partem dos valores-notícia (Galtung e Ruge, 1993), pressupõem um mundo factual de onde derivam as notícias, a abordagem discursiva parte do princí- 
pio de que não existe um mundo factual sem as estruturas conceptuais pelas quais essa realidade nos é disponibilizada (Bignell, 1997). Desta perspectiva, o campo fértil das notícias pode dizer-nos alguma coisa sobre como a forma como nos entendemos a nós e aos outros, enquanto membros de grupos e comunidades parcialmente construídos pelos media (Thompson, 1995: 35).

Um ponto de partida para esta análise é a qualidade narrativa das notícias para que vários autores têm chamado a atenção. Para Gaye Tuchman "os relatos de acontecimentos noticiosos são 'estórias' - nem mais nem menos” (Tuchman, 1999: 258) e, para Mário Mesquita, "a narratividade é uma característica dominante do texto jornalístico” (Mesquita, 2003: 130). O que é especialmente importante nesta característica é, como dizem Bird e Dardenne, o facto de que, ao "contar histórias", as notícias fazem mais do que informar:

[C]onsiderar as notícias como narrativas não nega o valor de as considerar como correspondentes da realidade exterior, afectando ou sendo afectadas pela sociedade, como produto de jornalistas e da sua organização burocrática, mas introduz uma outra dimensão às notícias, dimensão essa na qual as "estórias" de notícias transcendem as suas funções tradicionais de informar e explicar. A abordagem narrativa não nega que as notícias informam: os leitores aprendem com as notícias. No entanto, muito do que aprendem pode ter a ver pouco com os "factos", "nomes" e "números" que os jornalistas tentam apresentar com tanta exactidão. Estes pormenores - significantes e insignificantes - contribuem todos para o bem mais amplo sistema simbólico que as notícias constituem". (Bird e Dardenne, 1993: 165)

Também para Teun van Dijk (1997a), ${ }^{2}$ a notícia - enquanto género jornalístico - constitui-se, do ponto de vista formal, por uma super-estrutura narrativa e Fairclough defende que a análise narrativa é necessária para revelar como determinadas "construções da realidade na linguagem contribuem para a produção, reprodução, ou transformação das relações sociais existentes" (Fairclough, 1992: 87). Uma análise das notícias como narrativas porém, mais do que uma simples análise das suas "histórias", é uma indaga-

\footnotetext{
${ }^{2}$ A pista fornecida por Van Dijk sobre o esquema das notícias com uma sintaxe específica com determinados níveis hierarquizados de macro-estrutura semântica e com esquemas temáticos permite fazer uma análise discursiva muito detalhada, notícia a notícia, na medida em que estas estruturas organizam os significados de acordo com categorias fixas, de que se destacam as causas, os antecedentes ou as consequências (van Dijk, 1988: 41). Outro contributo importante para uma análise detalhada e singularizada das notícias é o de Allan Bell, para quem os jornalistas são "contadores de histórias profissionais da nossa época" (Bell, 1991: 147).
} 
ção sobre o papel desempenhado pelas convenções jornalísticas articuladas numa determinada forma narrativa que ajudam a constituir os jornalistas como "analistas experientes do mundo político", como intérpretes que procuram um significado dos actos políticos para os oferecer a um público que, só por si, pode ter dificuldade em perceber o significado dos acontecimentos (Schudson, 1993: 281).

O discurso jornalístico é, por outro lado, o resultado de um conjunto de pressupostos culturais que dão forma às notícias, construindo narrativas que sejam relevantes do ponto de vista da sua noticiabilidade e que, simultaneamente, façam sentido do mundo de uma forma aceitável. As rotinas jornalísticas são essenciais a esta construção e, como a investigação da comunicação política dos últimos 30 anos tem demonstrado (por exemplo, Tuchman, 1978; Gans, 1979; Herman e Chomsky, 1988; Wolfsfeld, 1997), ela tende a dar prioridade aos acontecimentos definidos pelas fontes noticiosas poderosas e importantes do ponto de vista social, político e cultural. Esta prioridade justifica-se, do ponto de vista da rotina noticiosa, pela sua estabilidade em termos de credibilidade e pela forma profissional como as fontes oficiais oferecem uma "dieta" de notícias, relativamente "pronta a consumir" por parte das redacções. Pelo contrário, os grupos de menor status social surgem nos media quando são alvo, precisamente, das acções dos grupos que detêm o poder ou quando associados a processos desviantes. O resultado é "o reforço e a amplificação das lacunas existentes entre a população maioritária e minoritária” (Avraham et al., 2000: 120).

Os estudos da imigração na imprensa têm reflectido maioritariamente sobre esta mesma questão na forma das ligações entre imigração e racismo (Cunha et al., 2002, Vala et al., Campbell, 1995; van Dijk, 1991, Teo, 2000), ancorando-se na tendência para os media reflectirem e reforçarem a distribuição de poder social e político. Muitas destas investigações mostram como, quantitativamente, sendo o grosso das notícias referentes a expulsões, detenções e criminalidade diversa, os media apresentam a imigração como uma ameaça, podendo despoletar processos de racismo e xenofobia. Qualitativamente, a análise tem-se também centrado nas formas de "racismo noticioso" frequentemente enraizadas nas estruturas e pressuposições da linguagem.

No entanto, as relações entre media e imigração não são unívocas, reflectindo antes uma ambivalência que deriva do facto de os media retirarem a sua substância comunicacional não apenas da orientação estratégica (captação de audiências, escrita rotinizada com fins profissionais, etc.), mas também da sua constituição como agentes do espaço público, isto é, meios de reprodução simbólica da comunicação, formações simbólicas tecnolo- 
gicamente enxertadas no mundo da vida. Neste processo, que é também de "agendamento", são construídas identidades e lugares de desvio e normalidade. Quando os imigrantes são estigmatizados como "problemáticos", mas também quando são relatadas as suas parcas histórias de "sucesso", constroem-se socialmente as suas identidades e também a do Estado nacional que os recebe: como a norma a que o desvio se opõe, ou como a terra onde os sonhos acontecem, onde os imigrantes - tantas vezes vítimas das "suas próprias gentes” - têm a possibilidade de ser reconhecidos e dignificados.

Estes são enquadramentos que se constituem como ferramentas importantes para analisar de que forma o discurso noticioso constrói a relação entre imigrantes, o Estado e suas instituições e os cidadãos em geral, numa análise qualitativa que poderá complementar outras análises quantitativas centradas nos conteúdos manifestos da cobertura noticiosa dos emigrantes. Este tipo de abordagem permite indagar o papel da linguagem no que é há muito reconhecido no jornalismo como a "construção social da realidade" (Tuchman, 1978) e, mais em particular, o importante papel do jornalismo na estruturação de um discurso público sobre a emigração. Apesar dos seus limites metodológicos, a relevância de uma análise discursiva da cobertura noticiosa dos emigrantes está no facto de os significados atribuídos à sua identidade, através da linguagem e de determinadas práticas discursivas, influenciarem a forma como o grupo é visto num contexto mais geral. A representação discursiva dos imigrantes determina, com efeito, tanto a forma como eles são percebidos e tratados na sociedade, como a própria forma como eles se percebem a si próprios.

É precisamente pelo carácter narrativo das notícias - pela sua forma de apresentar e ordenar o mundo descrevendo situações que envolvem cenários, personagens e acções - que podemos explorar a construção social dos imigrantes na imprensa. No que se segue, propomos, pois, testar a forma como o discurso jornalístico constrói episódios e "histórias" que focalizam as questões da imigração, remetendo-as para acontecimentos que, na verdade, são expressão de uma problemática política, social e cultural maior.

\section{A análise do discurso como metodologia de análise das notícias}

A tentativa de explorar as formas pelas quais a "realidade" dos imigrantes é construída dentro da linguagem, do discurso e das representações mediáticas, num processo de produção e de difusão da ideologia, constitui uma abordagem às notícias em termos discursivos que faz das suas representações não tanto uma "distorção" da realidade e dos seus participantes, mas uma forma de produção ideológica destes. O papel ideológico dos media no processo de reprodução social das nossas sociedades reside sobre- 
tudo no modo como continuamente trabalha os processos materiais produzidos na vida social, integrando-os em sistemas ideológicos consistentes e, "na medida em que as ideologias estão ligadas e nascem das práticas sociais e materiais e lhes dão expressão e articulação, os media têm, inevitavelmente, um efeito político na reprodução social” (Kress, 1983: 43).

A principal orientação da nossa análise é, pois, uma indagação das formas como a linguagem dos media afecta as identidades e as relações sociais. Deste modo, constitui uma tentativa de realçar a natureza discursiva e linguística do poder mediático (Fairclough, 1995: 2), nomeadamente nas suas formas de representar os acontecimentos e os actores sociais.

Refira-se que a análise do discurso - ao contrário da análise quantitativa do conteúdo das notícias - implica uma visão construtivista "forte" do mundo social, isto é, envolve um conjunto de pressupostos relativos aos efeitos construtivos da linguagem, sugerindo análises textuais detalhadas. Nelas, os utilizadores da linguagem são considerados membros de comunidades, grupos ou organizações, supondo-se que falam, escrevem ou compreendem a partir de uma posição social específica. Assim, o discurso é entendido, nesta metodologia, como uma prática social. Seguimos aqui a lição de Fairclough, entendendo que as notícias são enunciados linguísticos (sendo que o uso da língua é sempre um uso social, contextualizado e dirigido) e constituem-se como práticas discursivas de natureza sociocultural:

Com a utilização do termo "discurso", proponho-me a uma leitura da linguagem como um tipo de prática social em vez de uma actividade puramente individual ou um reflexo de variáveis situacionais. Isto tem várias implicações. Em primeiro lugar, implica que o discurso é um modo de acção, [...] bem como um modo de representação. [...] Em segundo lugar, implica que há uma relação dialéctica entre discurso e estrutura social. (Fairclough, 1992: 63-64)

Atendendo ao princípio básico da análise crítica do discurso de que a linguagem é uma prática socialmente determinada, procuraremos considerar características que nos permitam ver a inter-relação entre os processos ideológicos e a organização discursiva, com vista a explorar como são criadas e produzidas as ideias e objectos sociais por parte da comunidade jornalística. Neste processo, a ideologia surge-nos "numa concepção que procura ser de teor meramente descritivo" e que se refere

a sistemas de pensamento, de valores e crenças, por exemplo, que denotam um ponto de vista particular sobre o real, uma construção social da realidade, independentemente de aspirarem ou não à preservação ou à mudança da ordem social. A ideolo- 
gia é, nesta acepção, mais facilmente entendida não como uma imagem distorcida do real, uma ilusão, mas como parte do real social, um elemento criativo e constitutivo das nossas vidas enquanto seres sociais. (Gouveia, 1997: 26-27)

Partimos, igualmente, de um conceito de ideologia sugerido por Teun van Dijk, segundo o qual as ideologias são

modelos conceptuais básicos de cognição social, partilhados por membros de grupos sociais, constituídos por selecções relevantes de valores socioculturais e organizados segundo um esquema ideológico representativo de autodefinição do grupo. Para além da função social que desempenham, ao defender os interesses dos grupos, as ideologias têm a função cognitiva de organizar as representações sociais (atitudes, conhecimentos) do grupo, orientando assim, indirectamente, as práticas sociais ao grupo e, consequentemente, também as produções escritas e orais dos seus membros.(van Dijk, 1997b: 105-168)

Dos múltiplos elementos possíveis para proceder à análise das notícias, destacamos elementos como a estrutura narrativa das notícias, a lexicalização, as vozes exteriores e os participantes/papéis, sendo sobretudo da primeira e da última que aqui nos ocupamos.

Relativamente à estrutura da narrativa, já sublinhámos a importância deste modo discursivo na análise de textos mediáticos. Seleccionar factos e torná-los acontecimentos - isto é, torná-los legíveis como história - é uma das funções primeiras (e mesmo primárias) da textualidade jornalística. Este aspecto remete para as principais dominantes do processo narrativo: a sua dimensão temporal e antropomórfica; a atitude de distanciamento do seu enunciador e o seu pendor objectivo.

Quanto ao que designamos por participantes e papéis, procuramos indagar a representação discursiva e a forma como os actores sociais são designados, incluídos ou excluídos nos discursos, revelando os interesses e objectivos de quem os representa (van Leeuwen, 1996: 38). Tal permite verificar o tipo de papéis atribuídos a determinados grupos sociais: quem age, como age, em benefício de quem; serão essas acções transitivas ou intransitivas; serão veiculadas por formas verbais semanticamente disfóricas ou eufóricas? Este é para Theo van Leeuwen um elemento crucial: nem sempre a "acção sociológica é realizada pela acção linguística” (van Leeuwen, 1997: 169-222). Quer isto dizer que, além de recorrermos a operações linguísticas (a forma da frase, a omissão do agente da passiva, a estrutura sintáctica das proposições, a nominalização), para percebermos de que forma os discursos configuram e constroem os participantes, teremos também em conta 
aspectos semânticos e ideológicos como: processos de exclusão, topicalizações, categorização, transitividade (no sentido em que Fowler a define) ${ }^{3}$. Ao analisar como os actores sociais ocupam posições tópicas e que tipo de actores intervém como agentes ou pacientes nos processos, poderemos dar conta de como as notícias são discursos que constroem identidades, podendo induzir o leitor a percepcionar o mundo social de determinada forma, muitas vezes com base em modelos partilhados (Hall, 1980).

Seleccionámos, no ano de 2003, três notícias, uma escolha que não foi totalmente aleatória: tendo em comum o tema do trabalho, os excertos noticiosos encontram-se em jornais de perfis diferentes (Público, Jornal de Notícias e 24 Horas), correspondendo também a "acontecimentos" diferentes do ponto de vista jornalístico, como abaixo explicaremos. Para além do tema do trabalho, procurámos explorar linhas de continuidade entre as notícias, como o facto de serem relativas a diferentes imigrantes (um angolano, uma cubana e um grupo colectivo) e de darem a ver "instantes" diferentes mas comuns à imigração: as histórias de vida, o encontro com as vozes de autoridade e a sua abstracção num sujeito colectivo, objecto de olhar institucional. São também dados as ver diferentes actores sociais envolvidos na imigração: imigrantes, autoridades e instituições.

A quantidade dos textos analisados não é, na nossa perspectiva, muito relevante, pois a análise visa a estrutura, o estilo e os enquadramentos persuasivos dos textos, e não a sua representatividade estatística. Estamos, aliás, cientes de que, abdicando da representatividade estatística, incorremos em determinados perigos, como aqueles para que Hardt-Mautner adverte:

[O] perigo escondido é que a razão pela qual os textos foram inicialmente singularizados para a análise tenha sido o facto de, precisamente, eles não serem típicos, mas de facto invulgares, tendo, por isso, chamado a atenção do investigador. (Hardt-Mautner, 1995: 3)

No entanto, cremos que os excertos que passamos a analisar são exemplares de como a linguagem (jornalística, neste caso) nunca é inocente, mesmo que tenha por objectivo último a maior neutralidade possível. Além disso, cremos que dão a ver os mecanismos e rotinas de trabalho dos jornalistas, podendo também contribuir indirectamente para esse estudo.

\footnotetext{
3 "A Transitividade - parte da função ideacional da linguagem - é um poderoso e fundamental conceito de Halliday, fundamental na análise da representação [...] é o meio pelo qual a oração é utilizada para analisar eventos e situações de certos tipos." (Fowler, 1991: 70-71).
} 
Sublinhamos também que seleccionámos apenas dois segmentos textuais - títulos e primeiros parágrafos da notícia - assumindo o pressuposto de que ambos podem ser considerados nos planos macro-estrutural e super-estrutural, os mais importantes da notícia (van Dijk, 1988, 1991).

\section{A construção dos actores sociais da imigração na imprensa: uma análise de três casos}

\subsection{Vida de imigrante}

VIVO COM 46 EUROS POR MÊS

Desempregado desde Janeiro deste ano, Gomes Pedro, um angolano de 46 anos, só pensa em juntar algum dinheiro para poder voltar à sua terra natal. A passagem por alguns países da Europa, onde trabalhou, tem sido uma desilusão. Portugal está também longe de ser o paraíso com que sonhou. "Estou cá há cerca de oito anos. Primeiro, dois meses em Lisboa. Depois vim para o Porto trabalhar na construção da torre das Antas. Só que não tive sorte. Mesmo assim, arranjei trabalho, pouco depois, nas obras do Complexo Desportivo do Monte Aventino", conta ao 24 horas Gomes Pedro.

(24 Horas, 26/08/03)

Esta notícia pode ser considerada, na nossa análise, como fait-divers ${ }^{4}$, e retrata, num registo descritivo, a vida de um imigrante angolano. Inserido num jornal fortemente marcado pelo cariz popular, onde são narradas frequentemente histórias que apelam ao drama e à sensação, o excerto não

\footnotetext{
${ }^{4}$ Numa obra dedicada ao estudo da novela (como género narrativo literário), Cristina Robalo Cordeiro dedica um subcapítulo ao fait-divers como género jornalístico afim da novela, salientando a "clara cumplicidade temática, estrutural, sociológica" entre os dois géneros narrativos (Cordeiro, 2001: 39-44). Por seu lado, Reis e Lopes lembram que "[...] a representação narrativa [pode] ser entendida num sentido restrito como conceito afim da perspectiva narrativa: das várias opções de focalização permitidas pela perspectiva, decorrem imagens particulares da história, condicionadas (não só em termos sensoriais, mas também afectivos e ideológicos) pelo ponto de vista que modeliza a diegese." (Reis e Lopes 1994: 356). Por fait-divers, entendemos, no seguimento destas leituras, a narrativa de casos banais do quotidiano, que recorre a instrumentos e estratégias novelescos para anular o distanciamento do leitor, explorando a recepção hipersensível, sensacionalista e melodramática. Quer dizer, as notícias cuja representação em showing promova uma imagem da história geralmente emotiva, não contextualizada e aberrante: tal como os relatos breves da literatura, "ao nível da leitura, tudo é dado num fait-divers; as circunstâncias, as causas, o passado, a resolução; sem duração e sem contexto, ele constitui um ser imediato, total, que não reenvia para nada de implícito" (Barthes, 1964: 188-197). Assim, como Roland Barthes, acreditamos que a definição de fait-divers não passa exclusivamente pelo conteúdo noticiado, mas pela estrutura do discurso narrativo. Este género jornalístico põe em jogo uma estrutura fechada, onde os factos se relacionam por critérios de casualidade e de coincidência. Não está, pois, em causa tanto a associação habitual de fait-divers à noção anglo-saxónica de soft news - histórias de interesse humano que se contrapõem às hard news de cariz político ou económico -, mas sim a sua particular estrutura narrativa.
} 
apela necessariamente a essas características, apresentando-nos uma história frequente nas narrativas jornalísticas da imigração: a de um imigrante que vem para o nosso país em busca de um "sonho".

Começando pela análise do título ("Vivo com 46 euros por mês") - enunciado cuja importância na estrutura da notícia já foi destacada -, o primeiro aspecto que importa assinalar prende-se com o facto de estarmos perante um enunciado citado em reprodução mimética, cujo enunciador é omitido. Trata-se de uma frase declarativa, na primeira pessoa do singular, que focaliza a atenção do leitor para um universo pessoal e individual. Queremos com isto dizer que o título desta notícia cumpre, do ponto de vista pragmático, uma função relevante: modela o horizonte de expectativas do leitor, preparando-o para a leitura de uma história de vida particular, facto que, aliás, é confirmado pelo lead, cuja segunda parte é toda ela constituída por uma citação em reprodução mimética, onde o enunciador primeiro resume a sua história.

Para além deste aspecto, julgamos importante sublinhar o carácter apelativo deste título - característica comum a notícias fait-divers: o sujeito da frase é agente de um processo não deliberado, traduzido pela forma verbal "Vivo", que aponta para a descrição de um estado, não traduzindo nenhuma acção; este apagamento do sujeito é também conseguido, em nosso entender, pelo complemento circunstancial "com 46 euros por mês" que contribui para criar o efeito apelativo a que nos referimos. Trata-se de uma circunstância que, mais do que um pormenor descritivo, serve para chamar a atenção para a precariedade da vida do sujeito, baseando-se num processo de implicação: o leitor que conheça minimamente a realidade nacional captará esse sentido, sem que seja necessária uma referência explícita a essa constatação.

A fragilização e o apagamento deste sujeito são retomados na primeira proposição do lead - "Desempregado desde Janeiro deste ano, Gomes Pedro, um angolano de 46 anos, só pensa em juntar algum dinheiro para poder voltar à sua terra natal." - onde a posição tópica do adjectivo de carga disfórica "Desempregado" dá o tom ao texto e remete para uma posição secundária a identidade do participante (nome, idade e nacionalidade); para além disso, a acção que protagoniza está fora do seu controlo: o sujeito "só pensa em juntar algum dinheiro", isto é, restringe-se o carácter de acção do processo, através do recurso à forma verbal "pensa" e à construção da infinitiva "em juntar"; além disso, o advérbio "só" - que serve para atrofiar a acção do sujeito - também contribui para hiperbolizar a sua situação de fragilidade e não acção. Além disso, o determinante indefinido "algum" aponta para os limitados e pouco ambiciosos objectivos do sujeito, traduzidos num complemento circunstancial de fim "para poder voltar à 
sua terra natal": a modalidade de probabilidade acentua a incapacidade de o sujeito se assumir como actor da sua própria vida. Também nos parece digno de nota o recurso à metáfora de conotação emotiva "terra natal" que permite acentuar a desintegração do sujeito, como um deslocado, distante do seu país.

As duas proposições que se seguem - "A passagem por alguns países da Europa, onde trabalhou, tem sido uma desilusão. Portugal está também longe de ser o paraíso com que sonhou." - funcionam como suporte da primeira, através do qual o autor do texto tenta explicar as razões para a condição do protagonista, acentuando o seu estatuto de desprotegido.

A segunda frase do lead é muito sugestiva quanto à configuração de um percurso errante e fortemente disfórico. Para isso, contribuem algumas estratégias discursivas que passamos a destacar:

- Mais uma vez, o sujeito é remetido para um plano secundário: a única acção praticada ("trabalhou") aparece inserida numa oração subordinada, no interior da proposição;

- Topicaliza-se o substantivo "passagem" acompanhado de um complemento circunstancial de lugar ("por alguns países da Europa"), em que o determinante indefinido "alguns" comporta uma ideia de indefinição e de pluralização;

- Recorre-se a uma construção perifrástica ("tem sido"), com o verbo intransitivo de estado (ser), para acentuar o carácter reiterado e continuado da experiência negativa, projectada no nome predicativo ("desilusão");

Assim, toda esta proposição assenta numa implicação, pois aquilo que ela implicitamente expressa é a construção de um percurso de errância, afinal a motivação primeira da vinda do sujeito para Portugal. Esta construção continua na terceira proposição do lead, que tem como elemento chave a metáfora "paraíso com que sonhou". Afinal, este participante é protagonista de um sonho, não concretizado e não concretizável, como podemos inferir do uso da escolha lexicalizada do substantivo "paraíso". Curiosamente, as únicas ocorrências de léxico eufórico encontram-se na construção desta metáfora e remetem a possibilidade de afirmação do sujeito - precisamente pelo poder evocativo e intertextual da figura usada para um universo onírico, para um nível hipotético. Também nesta proposição, a posição tópica é ocupada pelo topónimo "Portugal" que aparece como a personificação distante (note-se o adjectivo "longe") do sonho do sujeito. Verifica-se, então, um paralelismo lexical e semântico entre a "desilusão" das etapas anteriores e o "sonho" distante do presente da personagem. 
Depois desta "introdução", em que o participante aparece como um paciente passivo e fragilizado, o autor da notícia cede-lhe a palavra, reproduzindo por citação mimética o seu discurso. Ao contrário do que é habitual, neste caso específico, a assunção da palavra pela personagem não the confere relevância, pois, na nossa opinião, o seu discurso funciona aqui como a confirmação do retrato construído pelo discurso do jornalista. A citação, tal como sucede no título da notícia, visa constituir-se como estratégia de autentificação, ausentando o filtro do olhar do jornalista e apresentando o testemunho directo do sujeito. Esta é, aliás, uma opção narrativa que tem como efeito anular o distanciamento do leitor, criando aquilo que em narratologia se designa por efeito de showing. Na nossa opinião, é de sublinhar que a fala desta personagem confirma a errância que lhe é atribuída pelo discurso do jornalista (traduzida pelos referentes espácio-temporais "Primeiro, [...] em Lisboa. Depois [...] o Porto") e reforça o campo semântico do "sonho" e da "desilusão", através da constatação "Só que não tive sorte.": a instabilidade do presente do sujeito é explicado pela voz do próprio como decorrente do factor destino.

O efeito final desta narrativa contribui, no nosso entender, para o que Stuart Hall designou por uma "leitura dominante" ou "preferencial" da notícia, pela qual o leitor partilha o código do texto e aceita e reproduz essa mesma leitura (Hall, 1980). ${ }^{5}$

\subsection{Imigração e autoridade}

\section{SAMPAIO COMOVEU-SE COM JULIETTE}

De entre os vários trabalhadores estrangeiros que Jorge Sampaio cumprimentou ontem, no âmbito de uma visita a uma empresa considerada exemplar na integração de imigrantes, Juliette foi quem mais o demorou. Depois de um diálogo circunstancial, o Presidente da República (PR) soube que a jovem de 26 anos, cubana, aprumada de farda amarela e azul, viu recusada a sua aptidão para exercer medicina em Portugal. [...] (Jornal de Notícias, 30/01/03)

\footnotetext{
5 As "leituras dominantes" ou "preferenciais" são, para o autor, as que não entram em contradição com a ideologia dominante: "Quando o espectador recebe o significado conotativo de um noticiário ou de um programa de actualidade política e descodifica as mensagens em termos do código de referência em que elas foram codificadas podemos dizer que o espectador está a operar dentro do código dominante." (Hall, 1980: 136). Stuart Hall - retomando a tipologia de Parkin -, fala ainda de outros tipos de leitura, como as "negociadas" e de "oposição" (Hall, 1980:136). Nas "leituras negociadas", os destinatários não se opõem totalmente à visão dominante mas questionam aspectos desse código e a construção da realidade baseadas nele: "Descodificar e elaborar uma leitura negociada contém uma mistura de elementos de adaptação e de oposição: reconhece-se a legitimidade das definições hegemónicas para as grandes significações (abstractas), enquanto, para as mais restritas, de nível situacional (situadas), constroem-se as regras próprias.” (ibid.:137). Quanto às leituras oposicionais, "o leitor pode entender perfeitamente a inflexão literal ou conotativa de um discurso, mas descodificar a mensagem de uma forma globalmente contrária”(ibid.: 137-138).
} 
Em termos das rotinas jornalísticas, esta notícia procede do pseudo-acontecimento que, no sentido de Boorstin, uma "presidência aberta" constitui (Boorstin, 1961). ${ }^{6}$ De notar que envolve um actor com um elevado grau de noticiabilidade - o Presidente - que, como procuraremos demonstrar e ao contrário do que seria de esperar, é, no entanto, "secundarizado" pela narrativa.

A notícia poderá ser considerada uma narrativa mista, assente num registo factual que é colonizado - estrutural e tematicamente - com fórmulas de fait-divers. Tendo como motivo uma visita presidencial a uma empresa que emprega trabalhadores imigrantes, o relevo que é aqui conferido quer às motivações políticas do acontecimento, quer à figura institucional do Presidente, não é, no entanto, suficiente para categorizarmos esta notícia no quadro da factualidade. O enfoque sobre o acontecimento de fundo é desviado para um aspecto particular - uma conversa entre o Presidente e uma das funcionárias - salientando-se o efeito surpresa, mais próximo da narrativa de fait-divers do que da narrativa factual. ${ }^{7}$ Podemos assim dizer que estamos perante uma notícia híbrida que se constrói pela colonização de estratégias discursivas de proveniência diversificada.

Estas características são, na nossa opinião, anunciadas pelo título da notícia: "Sampaio comoveu-se com Juliette". Neste enunciado, sublinhamos dois aspectos relevantes:

- O primeiro prende-se com a oposição de nomes próprios - um masculino e outro feminino: oposição em termos de reconhecimento - "Sampaio" tem um referente específico, reconhecido pelos leitores portugueses; "Juliette", além de não precisar na mente do leitor nenhum referente conhecido, também comporta outro factor de estranheza, por ser um nome estrangeiro. Esta oposição dos dois nomes (para mais colocados em posições estratégicas do enunciado - no início e no fim) causa assim um efeito de

\footnotetext{
${ }^{6}$ Por entre outras características, um pseudo-acontecimento, para Boorstin apresenta-se como um acontecimento não espontâneo, planeado com o primeiro fim de ser noticiado (Boorstin, 1961). 7 Por narrativa factual, entendemos uma notícia cuja estrutura formal obedece à super-estrutura tradicional deste género textual. Entendemos que a notícia é um género marcado precisamente pelas grandes dominantes do processo narrativo um tipo de enunciado fundado "numa atitude de variável distanciamento" (Reis \& Lopes, 1994) que descreve e modela discursivamente acções, submetidas a uma dinâmica temporal específica. Decorrente precisamente desta especificidade e de outras particularidades funcionais e comunicacionais, Teun van Dijk descreve uma superestrutura da notícia (van Dijk, 1997) que, como o autor sublinha, prevê uma articulação entre a macro e a superestrutura, precisamente nos enunciados que elegemos para a nossa análise - títulos e leads espaços paratextuais de configuração das principais macroproposições textuais, de reconhecida importância pragmática e estratégica. A narrativa factual é aqui entendida como aquela que se enquadra neste esquema tradicional, narrando acontecimentos políticos, económicos e sociais, e cuja macro-estrutura hierarquiza informação segundo critérios de importância.
} 
estranhamento, conseguindo despertar a curiosidade do leitor, acostumado a ler nos nomes próprios dos títulos jornalísticos a presença de figuras públicas.

- O segundo aspecto que nos parece digno de nota, na construção deste enunciado, prende-se com a transitividade da frase, processo fundamental para a construção da identidade dos participantes e dos actores sociais, como atrás sublinhámos através da referência ao trabalho de Roger Fowler. A forma verbal - "comoveu-se" - corresponde a um processo de estado o que anula o sujeito como actor: Sampaio, apesar de aparecer em posição tópica e de ser sujeito da frase, é claramente um paciente. Assim, o Presidente é sujeito passivo de uma acção provocada pelo outro participante - "Juliette" - afinal o verdadeiro agente do processo, apesar de secundarizado pela posição que ocupa na frase - complemento agente da passiva.

Estas duas estratégias revelam-se fundamentais tanto na construção da identidade dos dois participantes na notícia, como no delinear de um horizonte de expectativas que será correspondido pelo lead: trabalha-se um acontecimento político - uma visita presidencial, no âmbito da Presidência Aberta - reduzindo o seu alcance a um detalhe bizarro e pouco comum. Ao longo da primeira proposição do lead - "De entre os vários trabalhadores estrangeiros que Jorge Sampaio cumprimentou ontem, no âmbito de uma visita a uma empresa considerada exemplar na integração de imigrantes, Juliette foi quem mais o demorou." - confirma-se o posicionamento e o papel de cada um deste participantes:

- A topicalização e o protagonismo de Juliette são conseguidas através de: a antítese entre "os vários trabalhadores estrangeiros" (adjectivo indefinido "vários" implica uma generalização e um anonimato colectivo) e "Juliette" (nome próprio que implica um sujeito individual e concreto, com direito a nome próprio); o papel de paciente atribuído aos "vários trabalhadores estrangeiros" (complemento directo da acção assumida pelo Presidente traduzida por "cumprimentou") contrasta com o estatuto de agente de Juliette (sujeito activo topicalizado em início de uma oração - "Juliette foi quem mais o demorou" - e agente de um processo deliberado cujo paciente é o Presidente).

- Para mais, a circunstância política do acontecimento é claramente relegada para segundo plano, aparecendo numa oração intercalar - "no âmbito de uma visita a uma empresa considerada exemplar na integração de imigrantes" -, na qual, pelo recurso a uma nominalização ("uma visita"), a acção do PR é fragilizada.

Na segunda proposição do lead - "Depois de um diálogo circunstancial, o Presidente da República (PR) soube que a jovem de 26 anos, cubana, 
aprumada de farda amarela e azul, viu recusada a sua aptidão para exercer medicina em Portugal." - o protagonismo de Juliette é concretizado pelo recurso ao detalhe descritivo com que o jornalista a apresenta. Só aqui o nome Juliette é associado a uma identidade específica, individualizando um caso: queremos com isto dizer que, se até ao momento o destaque conferido a este participante foi conseguido através dos efeitos provocados em Sampaio, permitindo humanizar o Presidente da República, a partir deste momento, Juliette adquire uma identidade mais definida - "a jovem de 26 anos, cubana, aprumada de farda amarela e azul,"; mais do que um nome, o que se nos oferece agora é uma mulher categorizada pela sua juventude, pela sua nacionalidade e pelo uniforme da empresa que a emprega. Os detalhes descritivos - aparentemente insignificantes - presentes na expressão "aprumada de farda azul e amarela" remetem, na nossa opinião, para dois níveis de caracterização distintos, mais importantes do que pode parecer à primeira vista. $\mathrm{O}$ adjectivo "aprumada" decorre de uma modalidade apreciativa, através da qual o jornalista salienta em termos eufóricos o profissionalismo e atitude da funcionária. A referência à "farda azul e amarela" consegue, na nossa opinião, uma insinuação mais subtil: a um nível mais superficial, a farda tem a força de integrar o sujeito destacado no colectivo anónimo de trabalhadores estrangeiros da empresa; decorrente desta interpretação, a referência à farda contrasta claramente com o estatuto socioprofissional de um sujeito com "aptidão para exercer a medicina".

De facto, nesta proposição, ao contrário da lógica imposta até ao momento, Juliette torna-se paciente de um processo cuja agência é omitida expressamente - "viu recusada a sua aptidão para exercer medicina em Portugal.”. Sujeito de uma construção passiva, sem complemento de agente, Juliette é aqui vítima de um processo que a coloca numa posição de discriminada, exemplo paradigmático de um processo de integração deficiente. Não deixa de ser irónico o facto de a empresa cuja farda enverga ter sido categorizada inicialmente como "exemplar na integração de imigrantes" e de o caso específico apresentado na notícia ser o de uma mulher imigrante, a quem é vedado o exercício de uma profissão, socialmente valorizada, para a qual tem qualificações.

\subsection{A imigração e o olhar institucional}

IMIGRANTES COM TRABALHO DESADEQUADO

Permitir às mulheres imigrantes em Portugal conseguirem ocupações profissionais adequadas às suas habilitações é o desafio que se coloca ao Estado e à Organização Internacional para as Migrações (OIM), segundo Luís Rios. O chefe da missão da OIM em Lisboa considera necessário criar pontes entre as associações representativas 
dos imigrantes e as estruturas nacionais como o Instituto de Emprego e Formação Profissional, para que as mulheres imigrantes se insiram plenamente na sociedade. (Público, 12/03/03)

Este excerto noticioso, inserido num jornal de referência, é uma narrativa factual que quase poderíamos classificar como informação bruta (Rebelo, 2000: 117-118): trata-se de um texto que não tem acontecimento; funda-se exclusivamente na reprodução de uma voz institucional exterior que comenta a inserção das mulheres imigrantes na sociedade. Do ponto de vista noticioso, é uma notícia de "rotina", no seguimento de uma informação divulgada por uma fonte autorizada - a OIM de Lisboa.

O título da notícia - "Imigrantes com trabalho desadequado" - é um enunciado nominal (elipse de qualquer forma verbal) que topicaliza o substantivo "Imigrantes": o plural e a ausência de determinante apontam para uma generalização do participante social em questão. Mais à frente, no primeiro parágrafo da notícia, o leitor percebe que o verdadeiro participante desta notícia é as "mulheres imigrantes", restringindo-se assim o assunto a um grupo mais limitado. Apesar de lhe ser dada uma posição tópica, o título nominal anula o papel de agente do sujeito, indiciando-o como protagonista de um estado, lexicalizado disforicamente - "com trabalho desadequado”.

As duas proposições que compõem o lead são, como já referimos, citações em discurso indirecto que convocam a voz exterior de um actor social perfeitamente identificado - "Luís Rios", "O Chefe da missão da OIM". Dois comentários a este respeito que nos parecem significativos:

- Em primeiro lugar, mesmo antes de procedermos a uma análise do conteúdo e da forma destas proposições, percebemos que não existe neste lead nenhum facto notícia; aquilo que se veicula é um conjunto de expectativas e acções que o Estado português e duas instituições nacionais pretendem concretizar; assim, esta notícia assume funções de tribuna, de espaço controlado por certos grupos sociais de protagonismo público;

- Um segundo aspecto digno de nota prende-se com a forma como a representação do participante institucional Luís Rios é conseguida: tem direito a um nome próprio, tem direito à palavra e a uma identificação institucional - "O Chefe da missão da OIM". Em antítese ao modo de representação dos imigrantes, que surgem como grupo colectivo, anónimo e sem nenhuma intervenção directa, este participante social aparece com um protagonismo muito diferente.

Assim, na primeira proposição do lead - "Permitir às mulheres imigrantes em Portugal conseguirem ocupações profissionais adequadas às suas habi- 
litações é o desafio que se coloca ao Estado e à Organização Internacional para as Migrações (OIM), segundo Luís Rios." - as "mulheres imigrantes" aparecem como pacientes, cuja integração social depende da acção do Estado e da OIM. Por isso, a oração principal desta frase - uma infinitiva iniciada pelo verbo "permitir" - é sujeito do "desafio" (substantivo que classificamos como uma nominalização, pois transforma uma acção numa "coisa") colocado às duas entidades oficiais. Tanto o conteúdo semântico do verbo "permitir", como a nominalização de "desafio" remetem a adequação do trabalho das mulheres imigrantes para a esfera da probabilidade. Portanto, podemos dizer que a primeira proposição do lead é uma implicação que especifica a asserção contida no título.

Na segunda proposição - "O chefe da missão da OIM em Lisboa, considera necessário criar pontes entre as associações representativas dos imigrantes e as estruturas nacionais como o Instituto de Emprego e Formação Profissional, para que as mulheres imigrantes se insiram plenamente na sociedade." - topicaliza-se o "chefe da missão da OIM" que assume a função de participante agente de um processo controlado - "considera necessário criar pontes". Continuamos, deste modo, na esfera da acção futura que tem como pacientes as "mulheres imigrantes". Salientamos o recurso à metáfora "criar pontes" cuja significação reenvia para uma leitura implícita: a da separação de dois mundos aqui representados pela antítese "associações representativas dos imigrantes”/“estruturas nacionais”. Relativamente a esta oposição, gostaríamos de sublinhar ainda o facto de o enunciador ter a preocupação de discriminar as estruturas nacionais, referindo o "Instituto de Emprego e Formação Profissional", como exemplo de uma delas, omitindo e remetendo para o domínio da generalização as associações imigrantes.

As "mulheres imigrantes", apesar de serem o sujeito da oração subordinada final - "para que as mulheres imigrantes se insiram plenamente na sociedade" - são agentes de um processo verbal não controlado, traduzido pelo verbo "inserir", para mais conjugado no modo conjuntivo.

\section{Conclusão}

Partindo da análise destes três excertos de notícias, procurámos explorar as formas pelas quais a "realidade" dos imigrantes é construída dentro da linguagem, do discurso e das representações mediáticas, num processo de produção e de difusão da ideologia. Nesses curtos excertos são reveladas as qualidades narrativas das notícias, revelando uma visão do mundo da qual podemos retirar algumas conclusões sobre a forma como o discurso de imprensa projecta a relação - sempre paradoxal - entre o imigrante (o Outro, de fora do grupo) e a comunidade de acolhimento (o Nós, e suas instituições). 
Os textos correspondentes aos pontos 3.1. e 3.2. partem ambos de casos concretos e exemplares - as histórias pessoais de imigrantes - secundarizando a problemática mais geral que lhes é subjacente.

No texto de 3.1. encontramos uma narrativa que assume contornos de fait-divers e nos relata um caso de vida particular: o resumo da história de um imigrante angolano, desempregado; reduz-se a notícia a uma narrativa mínima, composta por uma personagem de evidentes contornos típicos, cuja representação assenta em estratégias de identificação - facilmente o leitor percepciona a história como mais um estereótipo, fundado no quotidiano real - e cuja vida é explicada por uma causalidade desconcertante, reduzida à sorte e ao destino, como se de uma personagem de ficção se tratasse. O sujeito, identificado como membro de um grupo social específico, é construído sempre em termos de defectividade: deslocado, desempregado, errante, e sem poder de controlar a sua própria vida, aparece como uma vítima da Sorte capaz de gerar sentimentos de piedade. Ao leitor não é oferecido um exemplo socialmente enquadrado e politicamente explicável, não lhe é exigido nenhum esforço de compreensão ou reflexão; antes, o que esta narrativa permite, fundando-se nas estratégias que acima rastreámos, é produzir efeito de "leitura dominante".

No texto do ponto 3.2., que tem a particularidade de ter como noticiabilidade um acto presidencial, o contraste entre as motivações da visita presidencial e o exemplo concreto desenvolvido funciona como factor de desconstrução: o actor Presidente é secundarizado na notícia, para dar relevo a uma mulher anónima, gerando nos leitores um conjunto de inferências que apontam para a estigmatização das mulheres imigrantes e para o défice de integração dos trabalhadores imigrantes. Do ponto de vista jornalístico, haverá razões que justifiquem este posicionamento aparente paradoxal dos seus actores. $\mathrm{Na}$ verdade, numa "não-notícia" enquanto acontecimento, como são os diferentes momentos de uma "presidência aberta" especialmente construída para chamar a atenção da comunicação social, faz sentido que o jornalista, para tornar a sua narrativa mais interessante, para poder contar uma história, como atrás referimos, concentre a sua atenção na construção de uma personagem "desconhecida" para os leitores, dramatizando-a, o que simultaneamente tem o efeito de "apagamento" da personagem "Presidente".

O texto do ponto 3.3., caso comum de notícia que decorre de uma rotina que é a informação de uma fonte "autorizada", é paradigmático da atribuição de identidades e papéis a dois grupos sociais que são apresentados e construídos por oposição: o anonimato e a passividade das mulheres imigrantes (que nem tiverem direito a presença explícita no título) opõem-se à 
acção futura, ao empenho e à abertura das instituições nacionais (agentes de todos os processos). A valorização da esfera de acção destas instituições é conseguida pelo recurso a um conjunto de palavras de conotação eufórica - "ocupações adequadas", "desafio", "insiram plenamente" - opostas à negatividade de "trabalho desadequado".

O confronto entre estes textos permite-nos verificar, apesar das diferenças que evidenciam, um denominador comum: o imigrante surge sempre investido de um papel passivo, totalmente dependente da acção das instituições nacionais. O único texto de dimensões futurantes (o texto 3.3.) limita-se a discriminar o conjunto de medidas que os agentes institucionais vão tomar, para tornar exequível a integração de mulheres imigrantes profissionalmente habilitadas. Nos outros dois textos (textos 3.1. e 3.2.), que, como vimos, focam casos particulares, predominam tempos pretéritos, que descrevem e narram a vida dos imigrantes, como se estes não pudessem gerir os seus próprios destinos.

A uni-los, encontramos, por fim, uma certa ordenação do mundo, da relação entre imigrantes e o país de destino, entre histórias de vida, poderes personalizados e humanizados e um Estado ancorado em organizações internacionais.

Como as análises de conteúdo das notícias demonstram, não há narrativas jornalísticas unas, nem o jornalismo produz conteúdos factuais uniformes ou tratamentos iguais dos imigrantes (Cunha, 2002). No entanto, a análise discursiva permite mostrar que a forma como nos entendemos colectivamente, como identificamos a pertença aos grupos e comunidades, é parcialmente construída pelos media. Mais do que um simples movimento reduzido às leis do mercado, a narrativa da cobertura noticiosa da imigração dá a ver um complexo social e político que as notícias ordenam e estabilizam. Nessa ordem, é possível encontrar dimensões sociais, políticas e de cidadania que, afinal, são o que decide que experiência particular ou acção social dominante emerge no discurso, que lugar ocupam os participantes na narrativa, que mito e histórias de nós e dos outros são contados.

\section{Referências Bibliográficas}

Avraham, Eli et al. (2000), "Dynamics in the News Coverage of Minorities: The Case of the Arab Citizens of Israel", Journal of Communication Inquiry, 24(2), 117-133.

Barthes, Roland (1964), "Structure du fait divers", in R. Barthes, Essais critiques. Paris: Seuil, 188-197.

Barkin, Steve M. (1984), "The Journalist as Storyteller: An Interdisciplinary Perspective”, American Journalism, Winter, 27-33. 
Bell, Allan (1991), The language of News Media. Oxford: Blackwell.

Bennett, W. Lance; Edelman, Murray (1985), “Toward a New Political Narrative», Journal of Communication, 35, 156-171.

Bignell, Jonathan (1997), Media Semiotics. An Introduction. Manchester: Manchester UP.

Bird, Elizabeth S.; Dardenne, Robert W. (1993), "Mito, registo e 'estórias': explorando as qualidades narrativas das notícias”, in Nelson Traquina (org.), Jornalismo: Questões, teorias e "estórias". Lisboa: Vega, 263-277.

Boorstin, Daniel (1961), The Image: A Guide to Pseudo-Events in America. New York: Harper \& Row.

Cádima, Francisco. R.; Figueiredo, Alexandra (2003), "Representações (imagens) dos imigrantes e das minorias étnicas na imprensa” (www.acime.gov.pt/ modules.php? name=Downloads\&d_op=getit\&lid=77; acedido em 31/10/2004).

Campbell, Christopher P. (1995), Race, Myth and the News. Thousand Oaks: Sage.

Cordeiro, Cristina R. (2001), Lógica do incerto - Introdução à teoria da novela. Coimbra: Almedina, 39-44.

Croteau, David; Hoynes, William (1997), Media/Society. Thousand Oaks: Pine Forge.

Cunha, Isabel F. et al. (2002), "Media e discriminação: um estudo exploratório do caso português”, Obercom, 5, 27-38.

Fairclough, Norman (1992), Discourse and Social Change. Cambridge: Polity Press.

Fairclough, Norman (1995), Media Discourse. London: Arnold.

Fowler, Roger (1991), Language in the News: Discourse and Ideology in the Press. London: Routledge.

Galtung, J.; Ruge, M. H. (1993), “A estrutura do noticiário estrangeiro”, in Nelson Traquina (org.), Jornalismo: Questões, teorias e "estórias". Lisboa: Vega, 61-73.

Gans, Herbert J. (1979), Deciding What's News: A study of CBS Evening News, NBC Nightly News, Newsweek, and Time. New York: Pantheon.

Gouveia, Carlos (1997), O amansar das tropas: Linguagem, ideologia e mudança social na instituição militar. Lisboa: Universidade de Lisboa (diss. de doutoramento).

Hall, Stuart (1978), "The Social Production of News", in St. Hall et al. (orgs.), Policing the Crisis: Mugging, the State, and the Law and Order. London: Macmillan, 53-77.

Hall, Stuart (1980), "Encoding/decoding”, in Centre for Contemporary Cultural Studies (org.), Culture, Media, Language: Working Papers in Cultural Studies, 1972-79. London: Hutchinson, 128-138.

Hardt-Mautner, Gerlinde (1995), Only Connect. Critical Discourse Analysis and Corpus Linguistics. Lancaster: Lancaster University.

Herman, Edward S.; Chomsky, Noam (1988), Manufacturing Consent: The Political Economy of the Mass Media. New York: Pantheon Books.

Kress, Gunther (1983), “Linguistic Processes and the Mediation of 'Reality': The Politics of Newspaper Language”, International Journal of the Sociology of Language, 40, 43-57. 
Mesquita, Mário (2003), “A personagem jornalística - da Narratologia à Deontologia”, in M. Mesquita, O quarto equívoco - Opoder dos media na sociedade contemporânea. Coimbra: Minerva.

Mouillard, Maurice ; Têtu, Jean-François (1997), Le journal quotidien. Lyon: Presses Universitaires de Lyon.

Rebelo, José (2000), O discurso do jornal. Lisboa: Editorial Notícias.

Reis, Carlos; Lopes, Ana Cristina M. (1994), Dicionário de narratologia. Coimbra: Almedina [4 ${ }^{\mathrm{a}}$ ed.].

Shudson, Michael (1993), "A política da forma narrativa: a emergência das convenções noticiosas na imprensa e na televisão”, in Nelson Traquina (org.), Jornalismo: Questões, teorias e "estórias". Lisboa: Vega, 278-293.

Teo, Peter (2000), "Racism in the News: A Critical Discourse Analysis of News Reporting in Two Australian Newspapers", Discourse E Society 11(1), 7-49.

Thompson, John B. (1995), The Media and Modernity. Oxford: Polity Press.

Tuchman, Gaye (1978), Making News: A Study in the Construction of Reality. New York: Free Press.

Tuchman, Gaye (1993), "Contando 'estórias”, Nelson Traquina (org.), Jornalismo: Questões, teorias e "estórias”. Lisboa: Vega, 258-262.

Vala, Jorge et al. (1999), Expressões dos racismos em Portugal. Lisboa: Imprensa de Ciências Sociais.

Van Dijk, Teun A. (1988), News as Discourse. New Jersey: Erlbaum.

Van Dijk, Teun A. (1991), Racism and the Press. London: Routledge.

Van Dijk, Teun A. (1997a), La ciência del texto. Barcelona: Paidós.

Van Dijk, Teun A. (1997b), "Semântica do discurso e ideologia”, in Emília R. Pedro (org.), Análise crítica do discurso. Lisboa: Caminho, 105-168.

Van Leeuwen, Teun A. (1997), “A representação dos actores sociais”, in Emília Ribeiro Pedro (org.), Análise crítica do discurso. Lisboa: Caminho, 169-222.

Wolfsfeld, Gadi (1997), Media and Political Conflict: News from the Middle East. New York: Cambridge UP. 